\title{
Co-production in BDS: The evidence from the Sri Lankan Microfinance Sector
}

http://doi.org/ 10.21272/fmir.4(3).63-71.2020.

\section{Ruwan Abeysekera}

Dr, Department of Finance, Faculty of Commerce and Management Studies, University of Kelaniya, Kelaniya, Sri Lanka

\begin{abstract}
Microfinance Institutions (MFIs), in addition to the provision of microcredit, also provide business development services (BDS) to owner managers in order to develop micro enterprises. BDS are non-financial services such as business training and access to information that help owner managers of microenterprises to develop businesses. In this respect, counsellors and trainers in MFIs co-produce BDS with owner managers. Co-production is the joint efforts of two parties, who together determine the output of their collaboration. The objective of this study therefore is to examine how co-production works in a BDS setting. A multiple case study method was used to carry out the study. Six MFIs were selected as cases and in-depth interviews were held with counsellors, trainers and managers to collect the data. The findings reveal that the expertise of counsellors, trainers and owner managers are the inputs for co-production. The outputs of co-production are twofold: MFI specific outputs and owner manager specific outputs. While MFI specific outputs are identified in better loan repayments rates, enhanced client satisfaction, and increased client retention, the owner manager specific outputs are denoted by better business knowledge, better sales, and profits. MFIs use counselling and training as modalities to co-produce BDS. There are a number of factors that affect the variability in coproduction including the readiness of counsellors and trainers, with a number of BDS provided under each modality. Therein, the findings of this study are beneficial to microfinance practitioners and policy makers. Furthermore, the findings also contribute to the knowledge domain of microfinance.
\end{abstract}

Keywords: business development services (BDS), co-production, microfinance, case study method

JEL Classification: M10.

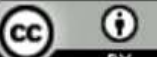

Cite as: Abeysekera, R. (2020). Co-production in BDS: The evidence from the Sri Lankan Microfinance Sector. Financial Markets, Institutions and Risks, 4(3), 63-71. http://doi.org/ 10.21272/fmir.4(3).63-71.2020.

(C) The Author, 2020. This article is published with open access at Sumy State University.

\section{Introduction}

Microfinance is the issuance of small unsecured loans (micro credit), business development services, savings, and insurance for people with low income (Khavul, 2010; ADB, 1997). Microfinance is provided by microfinance institutions (MFIS) targeting 2.8 billion people in the world whose daily income is less than two US dollars (World Bank, 2014; Easterly, 2006, p.165). One of the main objectives of microfinance is to develop microenterprises. For this purpose, MFIs use innovative solutions to clients/owner managers such as group lending and the increased provision of loans without collateral and pre-loan savings requirement that cannot be provided by the traditional banking system (CGAP, 2011; Khavul, 2010; ADB, 1997). Owner managers not only need microcredit but also require BDS to grow their businesses. Even though the initial constraint for microenterprises is microcredit, BDS is pivotal for the growth of such enterprises (Fisher and Sriram, 2002). BDS are non-financial services such as management training, access to information, and assistance in marketing that help owner managers to improve their knowledge, skills and in turn would help them to improve sales and profits in their business ventures (Khavul, 2010; Sievers and Vandenberg, 2007). BDS also enable MFIs to have increased loan repayments, satisfied clients, and enhanced client retention (Sievers and Vandenberg, 2007; ADEMCOL, 2001). MFIs use counsellors and trainers to provide BDS to owner managers (Abeysekera, 2016; Tilakaratne et al., 2009; Halder, 2003; ADEMCOL, 2001). Therefore, for a successful BDS intervention, there should be a collaboration/co-production between counsellors, trainers and owner managers (Abeysekera et al, 2017; Abeysekera et al, 2015). Co-production is the joint efforts of the two parties, who together determine the output of their collaboration (Parks et al., 1981). In effect, 
counsellors and owner managers are parties in co-production, so are trainers and owner managers. For example, the counsellor should work closely with owner managers to deliver BDS and help owner managers to reap benefits from BDS. Thus, co-production in BDS is vital for a successful BDS intervention (Abeysekera, 2016).

There are a number of studies made on BDS (Sievers and Vandenberg, 2007; Karlan and Valdivia, 2006; Goldmark, 2006; De Wildt, 2004; Halder, 2003; ADEMCOL, 2001). These studies mainly discuss the impact of BDS on owner managers and MFIs, sustainability of BDS, and the issues faced by MFIs in delivering BDS. However, there is no research made to find out how co-production can be implemented in BDS. Thus, this study intends to fill this gap. Therein, the main objective of the study is to examine how co-production can be implemented in BDS. The related research questions are: What are the inputs of co-production in BDS: What are the modalities of co-production in BDS: What are the outputs of co-production in BDS: and what are the factors that affect the variability in co-production. The remainder of the article is organized as follows. The paper first discusses the Literature. Secondly, it explains the research methodology. Next, it presents the findings of the study and lastly, the paper includes discussion, implications and concluding remarks. In this study, the client and owner manager is used interchangeably. Wherein the owner manager is the owner of the microenterprise.

\section{Literature Review}

\subsection{MFI categories}

MFIs can be divided into four categories (Jansson et al., 2004)

$\begin{array}{ll}> & \text { Non-profit MFIs (e.g. NGOs) } \\ > & \text { Bank MFIs } \\ > & \text { Non-bank MFIs } \\ > & \text { Cooperative/credit union MFIs }\end{array}$

Depending on the category of MFI, the provision of BDS may vary and hence influence the co-production in BDS. Despite the numerous benefits that BDS provide to both owner managers and MFIs, some MFIs think that the provision of BDS is a costly matter. This is partly due to the difficulty of recognizing the benefits of BDS over the cost incurred, in comparison to micro credit which provides direct revenue to MFIs through loan interest charged to owner managers/clients (Sievers and Vandenberg, 2007). Thus, cooperative MFIs and NGO MFIs may provide more BDS as they are concerned with achieving social objectives in addition to the financial objectives. However, bank MFIs may provide less BDS as they are funded by profit oriented investors and hence, think that providing BDS is costly (Galema et al., 2012; Maes and Foose, 2006).

\subsection{Lending Methodology}

MFIs use two lending methodologies targeting both group and individuals in order to provide their services.

Group lending: MFIs form groups consisting of 3-10 members/clients in order to provide services. The main objective of group formation is that microcredit is given to the members of the group, yet the group is responsible for the payment of microcredit. The members of the groups meet each other on a regular basis (i.e. via group meetings) and these meetings are attended by counsellors and trainers of MFIs. Group meetings allow MFIs to provide services including BDS (Khavul, 2010; Denotes and Alexandar, 2004). Individual lending: There is no group formation in individual lending and thus, MFIs demand collateral from clients to lend money. MFIs using individual lending find it difficult to provide BDS since there are no group meetings (Khavul, 2010; Denotes and Alexandar, 2004)

\subsection{Business Development Services (BDS)}

BDS are non-financial services that are provided by MFIs to boost competitiveness and lead to higher productivity, better product design, improved service delivery, and/or enhanced market access (Sievers and Vandenberg, 2007). BDS include marketing assistance, technical assistance, accounting and legal services, management/business training, productivity and product design, and access to technology and information. MFIs provide BDS to clients using counselling and training (Sievers and Vandenberg, 2007) 


\section{Counselling}

In this study counselling refers to the advice given by the counsellors of MFIs to owner managers of microenterprises in order to exploit growth opportunities and to manage the problems that they confront (Johnson, 1991). Counsellors build relationships with owner managers and assist them to recognize and achieve personal, entrepreneurial, and business goals (Canadian APEC, IBIZ, 2015; Johnson, 1991). MFI counsellors provide counselling on financial literacy, marketing, human resources, input supplies, linkages, and production (De Wildt, ADEMCOL, 2001). Counselling takes place at MFI's branch offices, at the owner manager's business premise or home, or even on the road (Abeysekera, 2016).

\section{Business training}

Business training refers to the MFI trainers' provision of training for owner managers of microenterprises and the follow up support given to solve practical problems (ADEMCOL, 2001; Gibb, 1997; Manpower Services Commission, 1975). Business training in microfinance covers areas such as financial literacy, operational training (i.e. business start-up advice, business idea generation, preparation of business plans, accounting, marketing, inventory control, costing, pricing, sales forecasting and quality), and strategic training (finding ways to access new markets, negotiating new contracts and networking) (Abeysekera, 2020; Henry, 2006). Business training can take place at community centres, temples, schools close to owner manager's home. Unlike counselling, business training has a long duration and could range from a few hours to a few days (Abeysekera, 2016).

\subsection{BDS linkages}

Dunford (2001) proposed three linkages to provide BDS to clients together with micro credit. These three linkages are given below.

$>\quad$ Unified: the same people from an MFI deliver both credit and BDS.

$>\quad$ Parallel: an MFI has two different departments that are separate cost centres and use different people to provide both credit and BDS.

$>\quad$ Linked (or partner): two distinct institutions (i.e. MFI and another institution); wherein the MFI offers credit and the other BDS while operating in the same area. In general, these institutions are linked by referring clients to each other and by initiatives such as undertaking joint marketing.

The type of linkage may have an impact on the co-production in BDS. For example, counsellors and trainers working in an MFI using parallel linkage may have more time to deliver BDS compared to the unified one.

\subsection{Co-production in BDS}

According to Parks et al (1981) co-production is the joint efforts of the two parties, who together determine the output of their collaboration. According to them co-production can be characterised by the following equation.

$\mathrm{Q}=\mathrm{cRP}^{\mathrm{d}} \mathrm{CP}$

$\mathrm{Q}=$ Output, $\mathrm{RP}=$ regular purchaser, $\mathrm{CP}=$ consumer purchaser, $\mathrm{c}=$ scaling factor, $\mathrm{d}, \mathrm{e}=$ output elasticities of each input.

This equation was used to guide this study. According to the equation, counsellors and trainers are the regular purchasers of co-production in BDS. Owner managers are the consumer purchasers. Output is the BDS provided by MFIs. Output elasticities are the readiness of counsellors and trainers and number of modalities of co-production in BDS (i.e. counselling, training). The research questions for this study were drawn using the above equation.

\section{Methodology}

Exploring co-production in BDS in the microfinance sector is a contemporary phenomenon and thus case study method was suitable as it helps investigate the phenomenon in the real life context. Furthermore, the case study method is ideal to identify issues and obtain an insightful understanding of the phenomena (Abeysekera, 2019; Yin, 2009). A multiple case study method was used for this study as it gives a theoretical generalisation as opposed to statistical generalization. Therein, six cases (i.e. MFIs) were selected for the study and this number was in the range of Eisenhardt's (1989) recommendation of four to ten cases to accomplish theoretical saturation.

To select cases and respondents for the study, a purposive sampling was used. MFIs were selected based on 
the type/category, lending methodology, and type of linkage. From each MFI a counsellor, trainer and manager were selected for in depth interviews.

The profiles of the MFIs selected for the study are given below in the Table 1 .

Table 1. Profiles of Mfis chosen for the study

\begin{tabular}{|l|c|c|c|}
\hline MFIs & Type/category of MFI & Lending methodology & Type of Linkage \\
\hline MFI1 & Public company & Group & Parallel \\
\hline MFI2 & Non-Bank & Group & Parallel \\
\hline MFI3 & Private bank & Individual & Unified \\
\hline MFI4 & Private company & Group & Unified \\
\hline MFI5 & NGO & Group & Parallel \\
\hline MFI6 & Government & Group & \\
\hline
\end{tabular}

Source: Compiled by the author.

Before the data collection began, a pilot study was undertaken in order to refine the semi structured questionnaire that was used to collect the data. For the purpose of data collection, 18 in depth interviews were conducted (i.e. three interviews from each MFI), and the duration of the interviews ranged from 45 to 60 minutes. The interviews were tape-recorded and transcribed. Moreover, informed consent was obtained from the interviewees for ethical reasons.

The main technique of analysis used to evaluate the data was thematic analysis. In addition, analytical techniques and strategies such as pattern matching and cross-case synthesis prescribed by Yin (2009) were used to analyse the data. By following the case study protocol to carry out the study, the reliability of the study was achieved. The construct validity was achieved by using multiple data sources. Pattern matching used in the data analysis helped achieve internal validity. Moreover, the external validity was accomplished due to multiple cases used.

\section{Findings}

The findings of the study are presented and organised based on the research questions.

\section{Research question 1: What are the inputs for co-production in BDS?}

The findings reveal that counsellors, trainers and owner managers bring their expertise to the co-production relationship. The findings further show that the expertise of counsellors and trainers can be defined in terms of knowledge gained through the qualifications and the experiential knowledge gained by working with owner managers. In this respect, counsellors and trainers have superior expertise compared to the owner managers. For example, counsellors and trainers had completed degrees, diplomas in business, had undergone training, and had years of experience. However, owner managers did not have expertise compared to counsellors and trainers. In fact, they had lower educational qualifications. Hence, due this gap in expertise, the superior expertise of counsellors and trainers helped co-produce with owner managers.

The superior expertise of the counsellors and trainers were witnessed in the data. The following is one of the quotations to substantiate this.

The manager enterprise development services of MFI-2 stated:

"Our counsellors and trainers are well qualified. They have degrees or diplomas in business. Further, we send them for training of trainers (TOT) programmes. Further, they have years of experience in counselling and training"

The low expertise of the owner managers emerged in the data. The following is one of the quotations to corroborate this.

The senior manager, microfinance of MFI-1 declared:

"Our clients/owner managers are often illiterate and do not possess good educational qualifications. However, they are clever to work with counsellors and trainers. Most of them had been deprived of their education due to the poor family upbringing" 


\section{Research question 2: What are the modalities of BDS in co-production?}

The findings show that MFIs provide BDS to owner managers through counselling and training. Thus, modalities in the co-production of BDS are counselling and training. The following table shows how counsellors and trainers provide BDS to owner managers through these modalitites. Table 1 was prepared by using the data gathered.

Table 1. BDS provided by MFIs through counselling and training

\begin{tabular}{|l|l|l|}
\hline \multicolumn{1}{|c|}{ BDS } & \multicolumn{1}{c|}{ Counselling } & Training \\
\hline Financial literacy & $\mathrm{x}$ & \\
\hline Linkages (loan, market, training) & $\mathrm{x}$ & \\
\hline Assistance in business registration & $\mathrm{x}$ & \\
\hline Assistance in loan application & & $\mathrm{x}$ \\
\hline Business plan registration & $\mathrm{x}$ & \\
\hline Assistance in input supplies & $\mathrm{x}$ & \\
\hline Formation of producer groups & $\mathrm{x}$ & \\
\hline Organising exposure visits, entrepreneurship competitions, trade fairs & $\mathrm{x}$ \\
\hline Knowledge in record keeping, marketing, pricing, quality, purchasing, costing & $\mathrm{x}$ & $\mathrm{x}$ \\
\hline Vocational skills training & & $\mathrm{x}$ \\
\hline $\begin{array}{l}\text { Business management (record keeping, accounting, costing, marketing, inventory } \\
\text { control, purchasing) training }\end{array}$ & & $\mathrm{x}$ \\
\hline Soft skills (communication skills, negotiation skills) training & & \\
\hline
\end{tabular}

Source: Compiled by the author.

\section{Question no 3: What are the outputs of co-production in BDS?}

The outputs are the BDS provided by MFIs. However, the real outputs are outcomes such as better loan repayment records for MFIs and better sales and profits for owner managers. The findings reveal that there are MFI specific co-production outputs and owner manager specific outputs. According to the findings, MFI specific co-production outputs are given below.

Broad socioeconomic goals such as the number of new ventures created and number of new job opportunities created:

$>$ Better loan repayments

$>$ Improved client satisfaction, relationship and retention

$>$ Improved deposit base

$>$ Social capital creation

$>$ Client graduation

Due to co-production in BDS, MFIs can achieve broader socioeconomic goals such as new venture and new employment creation. Further, MFIs can experience better loan repayments from the clients, as clients who obtained BDS would manage their businesses well and in turn would be able to pay back their loans. Due to the provision of BDS, the deposit base of the MFIs would grow as counsellors and trainers highlight the importance of savings to the clients. The clients who are satisfied with the BDS provided by MFIs would maintain better relationships with MFIs. Furthermore, the client dropout rate will be less and thus, higher client retention would be possible due to BDS provision. Therein, co-production in BDS enables the creation of social capital favourable to both MFIs and owner managers. Increased social capital could help managers of MFIs to implement new initiatives easily. For example, when a new branch opening of an MFI is organized, BDS clients will come in numbers and help the opening of the MFI branch. Due to such social capital, clients can improve the relationships with other owner managers that will also enhance their businesses and network. Due to the BDS provision, microfinance will expand to SME clients. The following are three excerpts to substantiate MFI specific outputs as explained above.

The enterprise development services manager of MFI-2 highlighted the importance of BDS in achieving social and economic goals, having better loan repayments records, and improved client satisfaction, enhanced relationships and client retention. He stated:

"There are many benefits we achieve from BDS. We can create new ventures and give more job opportunities. Further, clients are happy and maintain a good rapport with us. Moreover, we can retain clients with BDS otherwise they will go the competitors"

The Assistant General Manager of MFI-4 highlighted the achievement of an improved deposit base due to 
BDS. He expressed:

"Through BDS, we educate the clients about the importance of savings. This is a mutually beneficial thing. We can access low cost funding and owner managers can utilise saved money for their business and personal matters."

The Microfinance Manager of MFI-6 pointed out how social capital creation is favourable to the clients. He declared:

"Due to BDS provision, a client's social capital increases since the client links to many parties such as the government, NGOs, banks, groups, societies etc."

The Assistant General Manager of MFI-4 said how social capital creation is favourable to MFIs. He stated:

"We had a meeting yesterday at our Polpithigama branch for microfinance clients. Around 1300 attended without being persuaded. They love the credit and BDS programme. Thus, through credit plus (i.e. BDS), we have created social capital favourable to the bank. Even politicians cannot do this."

The manager of MFI-3 explained the client graduation due to BDS provision. He stated:

"Our model is different. We want our microfinance clients to graduate. Today's microfinance client can be tomorrow's SME client or corporate client. So we think by providing BDS we can help them graduate".

The findings show that co-production in BDS resulted in owner manager specific outputs such as improved sales and profits and improved knowledge and practice. All the respondents agreed and the following is one of the quotations to substantiate this.

The microfinance manager of MFI- 6 declared:

"BDS help owner managers to improve sales and profits in their business ventures. Further, it helps improve their knowledge and the practice".

\section{Question 4. What are the factors that affect the variability in co-production?}

The findings show that readiness and a number of BDS offered by each MFI affect the variability in coproduction. Readiness means the time available for counsellors and trainers to engage in co-production. The findings reveal that in comparison to counsellors working for MFIs having parallel linkages, the counsellors working for MFIs using unified linkages did not have much time to deliver BDS. Further, it was found that internal full-time trainers (e.g. MFI-1) had more time to deliver business training compared to the internal parttime trainers. Readiness of counsellors and trainers is evidenced by the following quotation.

Enterprise Development Services manager of MFI-1 expressed:

"We have two departments to provide microcredit and BDS. Thus, our counsellors working for BDS department have more time to focus on BDS rather than on micro credit. Further, we have a department for training with full time trainers. So these trainers have enough time to engage in training".

The findings also show that the range of services provided under the counselling and training modalities of coproduction, affect the variability in co-production. For example, certain MFIs provide a wider range of BDS through counselling and training (e.g. MFI-2), whereas there are other MFIs that provide fewer BDS. MFIs offering multiple BDS were able to interact with the clients more and hence could achieve a higher degree of co-production compared to those MFIs who offered a limited number of BDS. The variability of BDS range under each modality could be influenced by the type of linkage being used and the type of MFI. For example, compared to an MFIs using unified linkage, MFI-2 who uses parallel linkage has more time for their counsellors and trainers to deliver numerous BDS and hence could offer many BDS. This was evidenced in the data collected. Further, the type/category of MFI could affect the variability in co-production. It was found that private bank MFIs provided a limited range of BDS, whereas the government MFIs provided a wider range of BDS. This could be due to the profit motivation of the MFIs. A Bank MFI is a profit oriented entity and thus, would be reluctant to spend more on BDS, whereas government MFIs being often non-profit oriented would like to spend more on BDS and hence would offer a range of BDS.

This can be substantiated by the following quotation.

The microfinance manager of MFI-6 stated: 
"We are a government MFI and not profit oriented. We do not mind spending money on BDS due to the numerous benefits it brings. So, we provide many BDS to our clients"

\section{Discussion, Implications and concluding remarks}

The findings show that the expertise of counsellors, trainers, and owner managers is important in coproduction. Co-production in BDS takes place because there is a gap in expertise between the counsellors, trainers and owner managers, wherein counsellors and trainers have superior expertise. This finding is in line with Rice's (2002) study of co-production in business incubators. The findings also show that MFIs use counselling and training as co-production modalities. This finding can also be compared with the Rice's (2000) study. Rice (2002) found out that counselling, passive environmental intervention, and counselling are the coproduction modalities. However, Rice's study did not consider training as a modality. The findings of the present study reveal that there are two co-production outcomes (i.e. outputs). They are MFI specific outputs such as new venture creation, better loan repayments, client graduation, access to deposits, social capital creation, client satisfaction, and relationships and client retention; and owner manager specific outputs such as better sales and profits and better knowledge and practice. The extant literature (Rice, 2002; Karlan and Valdivia, 2006; Sievers and Vandenberg, 2007, ADEMCOL, 2001; Fisher and Sriram, 2002; ADB, 1997; Pestoff, 2012; OECD, 2011) on microfinance and small business supports the MFI related co-production outputs except the access to deposits. Thus, access to deposit is a new finding. The existing literature (Karlan and Valdivia, 2011; ADEMCOL, 2001; Copestake et al, 2001) is consistent with the owner manager related outputs. The findings show that readiness of counsellors and trainers and a number of BDS offered by the counsellors and trainers could affect the variability in co-production. The finding related to the readiness is supported by the Rice's (2002) study on business incubators. However, that study did not look at how contextual factors affect the variability in co-production. Nevertheless, the present study looks at how contextual factors such as linkage type and MFI type could affect the variability. Based on the findings of the study, it can be recommended that MFIs recruit counsellors and trainers with expertise, manage counselling and training co-production modalities effectively and efficiently, allow counsellors and trainers to engage more with the owner managers by allocating more time (i.e. increase readiness), and deliver more BDS so that a higher degree of co-production can be achieved. The findings of this study are useful to microfinance practitioners, policy makers and researchers in microfinance. Future research could focus on co-production in BDS in different countries and co-production in different products/services.

\section{References}

1. Abeysekera, R. (2020). Trainer expertise in business training: evidence from the Sri Lankan Microfinance Institutions. Management and Entrepreneurship: Trends of Development, 2(12), 8-21. https://doi.org/10.26661/2522-1566/2020-2/12-01

2. Abeysekera, R. (2019). Business Development Services (BDS) offered by microfinance institutions (MFIS) in Sri Lanka: Case Study as a research strategy. Si Lankan Journal of Management Studies, 1(1), 63-80. Retrieved from: http://repository.ou.ac.lk/handle/94ous1/1573

3. Abeysekera, R. (2016). Enhancing entrepreneurship in Sri Lanka: the provision of business development services (BDS) by microfinance institutions to support the self-sufficiency of microenterprises (Doctoral dissertation, Bournemouth University). Retrieved from: http://eprints.bournemouth.ac.uk/ 24721/1/ ABEYSEKERA \%2C\%20Ruwan_Ph.D._2015.pdf

4. ADB. (1997). Microenterprise development: Not by credit alone. Manila: Asian Development Bank. Retrieved from: https://www.findevgateway.org/library/microentreprise-development-not-credit-alone

5. Ademcol. (2001). Asociacio'n para el Desarrollo Microempresarial Colombiano and Women's Opportunity Fund: Bundling microfinance and business development services. A case study from ADEMCOL in Colombia, Microenterprise Best Practices. Washington, DC: United States Agency for International Development. Retrieved from: http://www.ruralfinanceandi nvestment.org/search/node/B undling\%20Microfinance $\% 20$ and $\% 20$ Business $\% 20$ Development $\% 20$ Services $\% 3 \mathrm{~A} \% 20 \mathrm{~A} \% 20 \mathrm{Case} \%$ 20Study \%20from\%20ADEMCOL \%20in\% 20Co lombia

6. Canadian Apec, Ibiz. (2015). Asia Pacific Economic Cooperation, International network of institutes of small business counsellors. Retrieved from: http://www.xlin.com/business-counselling.html [Accessed 12 July 2020].

7. CGAP. (2011). Advancing financial access to world poor [online]. Washington: Consultative group to assist the poor. Retrieved from: http://www.cgap.org/p/site/c/about/ [Accessed 20 July 2020].

8. Copestake, J., Bhalotra, S. and Johnson, S. (2001). Assessing the impact of microcredit: A Zambian case 
study. Journal of Development Studies, 37(4), 81-100. https://doi.org/10.1080/00220380412331322051

9. De Wildt, M. (2004). Linking business development services to financial services: The case of Financiera Solucio'n. Geneva: ILO. Retrieved from: http://www.bdsknowledge.org/dyn/bds/docs/422/MdRdWPeru.pdf

10. Denotes, V. and Alexander, S. K. (2004). The individual micro-lending contract: is it a better design than joint-liability? Evidence from Georgia. Economic Systems, 28, 155-176. https://doi.org/10.1016/ j.ecosys.2004.03.006

11. Dunford, C. (2001). Building better lives: Sustainable linkage of microcredit and education in health, family planning and HIV/AIDS prevention for the poorest entrepreneurs. Washington DC: Freedom from Hunger, commissioned by Microcredit Summit Campaign. Retrieved from: http://citeseerx.ist.psu.edu/ viewdoc/download? doi=10.1.1.475.301\&rep=rep1\&type=pdf

12. Easterly, W. (2006). The white man's burden: Why the West's efforts to aid the rest have done so much ill and so little good. New York: Penguin Press. Retrieved from: https://www.amazon.com/White-MansBurden-Efforts-Little/dp/0143038826

13. Eisenhardt, K. M. (1989). Building theories from case-study research. Academy of management review, 14 (4), 532-550. Retrieved from: https://www.jstor.org/stable/258557

14. Fisher, T. and Sriram, M. S. (2002). Beyond micro-credit: Putting development back into micro-finance. New Delhi: Vistar Publications. Retrieved from: https://policypractice.oxfam.org.uk/publications/beyond-micro-credit-putting-development-back-into-micro-finance122837

15. Galema, R., Lensink, R. and Mersland, R. (2012). Do powerful CEOs determine microfinance performance? Journal of management studies,49 (4), 718-742. https://doi.org/10.1111/j.14676486.2012.01046.x

16. Gibb, A. A. (1997). Small firms' training and competitiveness. Building upon the small business as a learning organization. International small business journal, 15 (3), 13-29. https://doi.org/10.1177\% 2F0266242697153001

17. Goldmark, L. (2006). Beyond finance: microfinance and business development services. In: Berger, M., Goldmark, L. and Miller-Sanabria, T., eds. An inside view of Latin American microfinance. Washington DC: Inter-American Development Bank, 1-27. Retrieved from: https:/www.findevgateway.org/sites/default/files/ publications/files/mfg-en-paper-an-inside-view-oflatin-american-microfinance-2006.pdf

18. Halder, S. R. (2003). BRAC's business development services - Do they pay. Small enterprise development, 14 (2), 26-35. Retrieved from: https://pdfs.semanticscholar.org/35f2/61b1cbfd070f04 $10 \mathrm{dadb} 2 \mathrm{e} 0707 \mathrm{a} 7 \mathrm{c} 0 \mathrm{c} 6 \mathrm{f} 3 \mathrm{f} 2 . \mathrm{pdf}$

19. Henry, S. (2006). Good practice in business development services: How do we enhance entrepreneurial skills in MFI clients? [Online]. Toronto: Alterna Savings. Retrived from: https://www.microcreditsummit.org/wp-content/uploads/2019/11/30 Henry.pdf

20. Jansson, T., Rosales, R. and Westley, G. (2004). Principles and Practices for Regulating and Supervising Microfinance. Washington, DC: Inter-American Development Bank. Retrieved from: https://publications.iadb.org/publications/english/document/Principles-and-practices-for-regulating-andsupervising-microfinance.pdf

21. Johnson, D. J. (1991). Counselling business startups and owner managers of small firms: a psychological study, Part 1. Journal of Workplace Learning, 3 (5), 10-14. https://doi.org/10.1108/EUM0000000002866

22. Khavul, S., 2010. Microfinance: Creating Opportunities for the Poor? Academy of management perspectives, 24 (3), 58-72. https://doi.org/10.5465/amp.24.3.58

23. Karlan, D. and Valdivia, M., 2011. Teaching entrepreneurship: Impact of business training on microfinance clients and institutions. Review of economics and statistics, 93 (2), 510-527. https://doi.org/10.1162/REST a 00074

24. Maes, J. and Foose, L. (2006). Microfinance and non-financial services for the very poor: digging deeper to find keys to success. Washington, DC: Seep Network - Poverty Outreach Working Group. Retrieved from: https://pdfs.semanticscholar.org/fd83/74248b47dfe00c9415c8c6858e214a0f9ec6.pdf

25. Manpower services commission. (1975). Management training and the development in the small firm and the role of industrial training boards. Sheffield: Mimeograph. Retrieved from: https://discovery.nationalarchives.gov.uk/details/c/F259715

26. OECD. (2011). Together for better public services. Partnering with citizens and civil society. Paris: OECD. 
Retrieved from: https://www.oecd.org/gov/togetherforbetterpublicservices partneringwithcitizen sandcivils ociety.htm

27. Parks, R. B., Baker, P. C., Kiser, L., Oakerson, R., Ostrom, E., Ostrom, V., Percy, S. L., Vandivort, M. B., Whitaker, G. P. and Wilson, R. (1981). Consumers as coproducers of public services: some economic and institutional considerations. Policy studies journal, 9(7), 1001-1011. https://doi.org/10.1111/j.15410072.1981.tb01208.x

28. Pestoff, V. (2012). Co-production and third sector social services in Europe. In: Pestoff, V., Brandsen, T. and Verschuere, B., eds. New public governance, the third sector and co-production. New York: Routledge, 13-34. DOI: 10.2307/41683096. Retrieved from: https://www.jstor.com/stable/41683096

29. Rice, M. P. (2002). Co-production of business assistance in business incubators - An exploratory study. Journal of business venturing, 17(2), 163-187. https://doi.org/10.1016/S0883-9026(00)00055-0

30. Sievers, M., and Vandenberg, P. (2007). Synergies through linkages: who benefits from linking microfinance and business development services? World development, 35 (8), 1341-1358. https://doi.org/10.1016/j.worlddev.2007.04.002

31. Tilakaratne, G., Galappattige, A. and Perera R. (2009). Promoting empowerment through microfinance in Sri Lanka, economic and political empowerment of the poor- Sri Lanka. Sri Lanka: Centre for policy dialogue, South Asia Centre for policy studies. Retrieved from: https://www.ips.lk/economic-andpolitical-empowerment-of-the-poor-promoting-empowerment-through-microfinance-programmes/

32. World Bank. (2014). Poverty Review [Online]. Washington DC: World Bank. Retrieved from: http://www.worldbank.org/en/topic/poverty/overview [accessed 17 July 2020].

33. Yin, R. K. (2009). Case-study research: Design and methods 4th edition ed. London: Sage. Retrieved from: https://www.amazon.com/Case-Study-Research-Methods-Applied/dp/1412960991 